Journal of Education and Vocational Research

Vol. 5, No. 4, pp. 216-227, December 2014 (ISSN 2221-2590)

\title{
Effect of Modes of Video Presentation of Metacognitive Strategies on Secondary School Students' Achievement in Reading Comprehension in North Central Nigeria
}

\author{
Pius Adakole Ijiga \\ College of Education, Oju, Benue State, Nigeria \\ ijigapius@yahoo.com
}

\begin{abstract}
Many senior secondary school students struggle with reading comprehension of expository texts in Nigeria, leading to mass failure in the Senior School Certificate Examinations conducted by the West African Examination Council (WAEC). Research on improving reading comprehension has dwelt on isolated reading strategies taught the learners through the conventional lecture method. No study has explored the effect of video-based training on metacognitive strategies and verbal ability on students' achievement in reading comprehension. This study, therefore investigated the effect on achievement in reading comprehension of three modes of video instruction in metacognitive strategies of senior secondary school students in North Central zone of Nigeria. It also examined the main and interaction effects of verbal ability level, gender and treatments on achievement in reading comprehension. The study used a quasi-experimental post-test only equivalent group design. Three secondary schools were selected from three States in the North Central geo-political zones in Benue, Nasarawa and Kogi States. In each of the three schools, a total of 120 senior secondary school (SS II) students of both sexes were randomly sampled and assigned to three experimental groups and a control group. The study was guided by five hypotheses which were tested at $\mathrm{p}<0.05$ significant level. A Reading Comprehension Achievement Test (RCAT), developed by the researcher and validated by experts, was the main instrument used for data collection. The data collected were analyzed using t-test and Analysis of Variance (ANOVA). The research findings indicated significant effect of Drill and Practice Video Instructional Mode (DPVIM), Interactive Video Instructional Mode (IVIM), and main and interaction effects of verbal ability level and treatments. No significant effects on achievement in reading comprehension were found for Tutorial Video Instructional Mode (TVIM) and main and interaction effects of gender and treatments. Based on these findings, it is recommended that reading comprehension teachers should make use of video instruction in developing comprehension skills of secondary school students in Nigeria.
\end{abstract}

Keywords: Video-Mode, Instruction, Metacognitive, Strategies, Comprehension

\section{Introduction}

One of the challenges facing school system in Nigeria today is that of helping students not only to read but also to become good comprehenders. This is because reading text with comprehension is the ultimate goal of reading instruction and the skill is critical to success across domains of life activities. According to Eze (2007), a child's success in school hinges on his ability to read and comprehend learning materials. There is ample research evidence to support the fact that poor performance in school subjects often stems from students' failure to comprehend vital contents of subject matters and the questions asked or the instructions given during examinations (e.g Robinson, 2000). The effects of this deficiency are also noticeable in class assignments and examination scripts where teachers often discover that students have 'misread' questions. In Nigeria, many students lack stimulating and enriched background preparations necessary for good readership and comprehension. The reading culture among secondary school students and the larger Nigerian society is at low ebb. Yet learners are faced with increased range of learning experiences as they now offer more subjects in schools than did those of two decades ago. They therefore have enormous reading tasks but are less equipped to comprehend such tasks (Eze, 2002). This problem is further compounded by the existence of teachers, especially, at the secondary school level that according to Oyetundc \& Muodumogu (1999) would seem not to know what to do to develop reading comprehension skills in students. Many of such teachers lack the necessary methodological base, teaching resources, initiatives, and motivation to guide learners; and their desire to achieve results is minimal.

Text comprehension is a complex cognitive skill in which the reader constructs meaning by using all the available resources from both the text and previous knowledge. These resources assist readers in utilizing lexis and syntax, retrieving their meanings from one's mental lexicon, making inferences and 
employing schemata (Donin, Graves \& Goyette, 2004; Mikkink, Hulstin \& Smith, 2005). Similarly, studies demonstrate that successful comprehension does not occur automatically or by merely reading more text. Rather, it depends on directed cognitive efforts referred to as metacognitive strategies, which consist of knowledge about, and regulation of cognitive processing (Bazerman, 1985; Pressley \& Afflerbach, 1995). Simply put, metacognitive strategies refer to some set of specific procedures that help readers to take conscious control of reading by planning and selecting some reading strategies, monitoring the progress of reading, correcting errors, analyzing the effectiveness of reading strategies, and changing reading behaviors and strategies when necessary. Metacognitive strategies are used to monitor, control and advance the search for meaning. Most language scholars subsume metacognitive strategies under three major categories namely: Text preview or pre-reading strategies, during reading strategies and post reading strategies (Flood, Lapp \& Jenson, 2003; EI-Koumy, 2004). Pre-reading strategies include text preview (by looking at the title, pictures, prints and diagrams), prior knowledge activation and purpose setting. During reading strategies include skimming, use of context clues to figure out unknown words, paraphrasing the authors' words, main idea identification, text noting strategies (such as highlighting, underlining, circling, copying keywords, phrases or sentences, diagramming, making notes on margin, etc.). Post reading strategies involves summarizing, retelling of plot of story, evaluating ideas contained in the text against background or prior knowledge. Because of their strategic importance, these three sets of metacognitive strategies are selected for use in this study.

Since metacognitive strategies are complex, Pressley (2002) proposed explicit teaching of the strategies. The National Reading Panel (2005) linked improvements in comprehension with instructions in metacognitive strategies by claiming that the rationale for explicit teaching of metacognitive strategies is that comprehension can be improved by teaching students to use specific inherent cognitive strategies. Thus, when readers have difficulties understanding a text, they have to be able to use the right strategies to correct their understanding. Instructions then in metacognitive strategies provide readers with the steps that they can take to resolve reading problems as they arise. Even though, the benefits of explicit teaching of metacognitive strategies in improving readers' comprehension skills have been stressed and documented, the role of newer media in such instructional presentation and learning has not been explored, Ogunmilade (1989) noted that when educational media are wisely and judiciously applied to the teaching and learning process, they make learning to become more productive, concrete and resultoriented. Consequently, considerable confidence is placed in the value of educational media in enhancing the development of reading comprehension skills. Video, a selection and sequence of messages in an audio-visual context, has emerged as one of the instructional media contributing effectively to language learning. Ortiz (2004) and Goldman (2005) subscribed to the dynamic impact of video instruction on language learning when they declared that apparently, the video instructional technology seems a solution to some of the limitations of television educational broadcast. This is so because television educational broadcast applies mass communication strategies in an attempt to serve the specific learning requirements of the individual learner, coupled with inability of the individual to pause and reflect, or even take notes. But video can repeat instructional information or demonstrate as many times as desired, thereby enabling learners to learn with ease.

Video has been proven to be an effective resource in teaching English as a foreign/second language (EFL/TSL), and it has received a great deal of attention from researchers (Fante, 2007; Watts, 2007; Hannatin \& Trip, 2007). Researchers have indicated that multimedia learning materials are more useful than traditional paper-based instructions (Markey \& Ho, 2008; Cannin \& Wilson, 2006; Balatova, 2004; Mayer \& Moreno, 2003; Rose, 2003). Videos which provide visual, contextual and non-verbal input provide foreign language learners with simulation visual and aural stimuli which can make up for any lack of comprehension resulting from reading directly from texts (Stepsus, 2007; Omoniyi, 2007; Rammal, 2005; Seo, 2002). Several previous studies have shown that such videos are highly accepted by learners during the learning process (Choi \& Johnson, 2005; Choi \& Johnson, 2007; Ho, 2008). However, the instructional video used in the above earlier studies was primarily either broadcast through TV programs or stored in CD-ROMs. The linear nature of such video instructions produced inconsistent results. This is why this study investigates both the analogue video instructional mode alongside the more modern digital interactive video mode. Recent advances in multimedia and communication technologies have resulted in powerful learning system with instructional video components. The emergence of non-linear, interactive digital video technology allows students to interact with instructional video. This may enhance learner engagement, so improve learning effectiveness. A major media attribute of interactive video is random access to video content-users can select or play a segment with minimal search time (Lobb \& Cartwright, 2007). 
Video instruction has several modes: Interactive, Tutorials, Simulations, Dynamic, Games, Drills and Practice, Integrated learning system mode (Rajasekar, 2009; Harwood \& McMahon, 2007; Yang, 2005). Several studies have also been conducted to examine the efficacy of the different modes (Simpson, Cumley \& Novak, 2007; Omoniyi, 2007). The Drill and Practice Video Instructional Mode (DPVIM) for instance, is one of the most effective modes in language instruction. It is so .designed that it provides repeated drilling of the same material until a skill is not only-learnt but is brought to a state where the response becomes automatic. This is in line with the objectives of language skill development which is to teach language skills and strategies repeatedly in order to reach desired standard of proficiency. According to Yang (2005), the usual application of a training approach in language learning involves drill-and-practice, where the assumption is that repetition and near-repetition is needed to 'internalize' a piece of behavior that can be used spontaneously. A video 'drill and practice' program takes over the human trainer and can provide the kind of endlessly patient and flexible supervision which the class teacher often cannot spare the time for. The Video Drill and Practice Mode can thus be applied for training language skills of reading, listening; writing and speaking and exercises in phonetics and phonology, vocabulary, grammar and for administering interactive exercises (Yang, 2005).

The Tutorial Video Instructional Mode (TVIM) takes the characteristics of the self-instructor device called 'teaching machine' developed by Pressey in 1926. The mode takes on the responsibility for main teaching without active participation of the teacher. As opposed to the Drill and Practice mode, it presents the initial learning materials to the students and a set of questions for students to respond to. Should students demonstrate inability to answer the questions, more textual materials are presented. The tutorial mode is designed in form of a self-instructional course package-on video, comprising frames, stimuli (questions) and responses. The mode requires that the learner goes through the frames and responds to the questions at the end of each frame. In essence, the tutorial mode makes the video a teaching machine 'using the principles of programmed instruction. The characteristics of the mode include text presentation in small-steps, active learner participation in the learning process, feedback and reinforcement.

According to Watts (2007), Interactive Video Instructional Mode (IVTM) is one of the most new exciting technological developments to emerge in the last decade and it has far reading implications for language teaching and learning. In this mode both large and small media systems from video player, video monitor and peripherals are used to merge video image with computer graphics, using some computer software. Today, many new computers are produced with interface cards that can comply with home video disc to enhance instructional quality. The mode permits meaningful interactions of the teacher, the media and the learner in an instructional process using multi-media and computer projections. A number of factors influence reading comprehension. They include among others, learner's verbal ability and linguistic competence, readability level, gender and reading culture. Verbal ability is said to affect reading comprehension because students need a reasonable mastery of verbal reasoning skills to be able to read and comprehend texts, listen to and understand the teacher's explanations, and express accurately, what he has read. In this regard, Rubin (2001) examined the curriculum relevance of language arts as an integral part of reading comprehension and stated that it includes the four basic applications of language: reading, writing, speaking .and listening. The extent verbal ability will influence reading comprehension when learners are trained to acquire metacognitive skills by video presentation is not known.

Gender has also become contemporary focus for language researchers because of the influence they exert on language learning and achievement (Ezewu, 2002; Giftma, 1973). For instance, (Giftma, 1973) indicated that gender is relevant in the study of language performance of students because research show that girls arc better than boys in reading and verbal skills while boys are better in manipulations and physical productive tasks. But Ogunkola (1998) did not indicate girls' superiority over boys in reading and verbal reasoning. More studies are required to put this contention to rest. The objective of this study, therefore, is to determine the effect of Drill and Practice Tutorial and Interactive Modes of Video Instruction in Metacognitive Strategies on Senior Secondary School Achievement in Reading Comprehension in North Central Nigeria. The main and interaction effects of verbal ability and gender are also investigated.

Hypotheses: In view of the above stated objectives, the study tested the following hypotheses at $p<0.05$ significant level: 
- There is no significant difference in the mean achievement scores of students exposed to instructions in metacognitive strategies on Drill and Practice Video Instructional Mode (DPVIM), Tutorial Video Instructional Mode (TVIM) Interactive Video Instructional Mode (IVIM) and the conventional method in reading comprehension.

- There is no significant influence of verbal ability on students' mean achievement scores in reading comprehension.

- There is no significant influence of gender on students' mean achievement scores in reading comprehension.

- There is no significant interaction effect of mode of presentation of metacognitive strategies and verbal ability on students' mean achievement scores in reading comprehension.

T-test of independent mean was used to test hypotheses 1-3, while Analysis of Variance (ANOVA) was used to test hypotheses 4 and 5.

\section{Methodology}

The study was conducted using the quasi-experimental post-test only, equivalent group design. The homogeneity of the research subjects was established using their grade level (all SS II students) in government grant aided school in the three States as a standard variable. The sample consisted of $360 \mathrm{SS}$ II students drawn from three government grant-aided schools in the three States of Benue, Nasarawa and Kogi in North Central Nigeria. Purposive sampling technique was used to select the schools. In each of the schools selected, 120 students were randomly sampled and assigned to four classes of 30 students each. Treatments and controls were randomly assigned to each of the groups in three selected schools. Two instruments were used to collect data for the study: Reading Comprehension Achievement Test (RCAT) and Verbal Ability Test (VAT). The RCAT is a multiple choice and short answer reading comprehension test with five options per item. It was developed and produced by the researcher in line with a test blueprint which was based on the three levels of reading comprehension: literal, inferential and evaluative levels. The test items were generated based on selected contents and objectives of reading comprehension in the English language curriculum approved for SS II students in Nigeria. Kuder Richardson, (KR-20) formula was employed to determine the reliabilities estimates of the RCAT. The reliability coefficient of the test was 0.75 .

The Verbal Ability Test (VAT) is a forty five item multiple choice Verbal Aptitude Test. It was adopted from Ibode (2010). The instrument is divided into seven points as follows: word patterns, words describing words, words arrangement and meaning, sentence arrangement, odd words, word formation, order of size. The reliability of the VAT is 0.83 , indicating satisfactory reliability. Four materials were used for the research. They are;

a. Metacognitive Strategy Instructional Manual (MSIM).

b. Tutorial Video Instructional Mode (TVIM)

c. Drill and Practice Video Instructional Mode (DPVIM)

d. Interactive Video Instructional Mode (IVIM)

The Metacognitive Strategy Instructional Manual (MSIM) is an instructional guide or lesson plan to be employed in the teaching of the control group by utilizing the conventional method of teaching. The MSIM is in hard copy form as instructional guide for the control group. It was developed by the researcher. The Tutorial Video Instructional Mode (TVIM) is a video programmed course package designed by the researcher. This course package which is a self-learning program was employed in the teaching of the Experimental Group I. It consists of video instruction on metacognitive strategies whose presentation is through tutorial, mode, comprising frames, stimuli (questions) and correct responses. The TVIM requires that a learner goes through the frames and responds to the questions at the end of each frame. The Drill and Practice Video Instructional Mode (DPVIM) is a video instructional package, which presents textual materials for practice. It provides unlimited opportunities for students to practice desired skills and receive feedback on their performance. Its' main characteristics is providing repeated drills of skills on video until they become over-learnt or automatic. The mode requires that the learner practices the presented textual information through repetition. The mode also features -sound clips, pictures and animation to support practice and learning.

The Interactive Video Instructional Mode is a video program course package designed by computer system programmers. It consists of video and sound clips, pictures and animations, and features of 
interactivity. It was used for experimental Group III. The mode provides opportunity for meaningful interaction between the teacher, the learner and the media in instructional setting. The treatments for the study were metacognitive strategy instruction presented on three modes of video instruction. Three groups were used for the study. They include:

Experimental Group I: The treatment in this group consisted of metacognitive strategy instruction presented on Tutorial Video Instruction Mode (TVIM).

Experimental Group 2: The treatment here was metacognitive strategy instruction presented on Drill and Practice Video Instruction Mode (DPVIM).

Experimental Group 3: The treatment in this group was metacognitive strategy instruction presented on Interactive Video Instructional Mode.

Control Group: Students in the control group were exposed to metacognitive strategy instruction via conventional method.

The students in the four groups received two - 45 minutes metacognitive strategy instruction a week for six weeks. The metacognitive strategies taught were: Pre-reading Strategies, During reading strategies and Post reading strategies.

\section{Results}

Presentation of results was guided by the hypotheses.

Ho1: There is no significant difference in the mean achievement scores of students exposed to instruction in metacognitive strategies on Drill and Practice Video Instructional Mode (DPVIM), Tutorial Video Instructional Mode (TVIM), Interactive Video Instructional Mode (IVIM) and conventional method in reading comprehension.

Table 1: Mean scores and Standard Deviations of students; post-treatment scores in RCAT.

\begin{tabular}{lllll}
\hline $\begin{array}{l}\text { Experimental } \\
\text { Group }\end{array}$ & $\mathbf{N}$ & Mean & $\begin{array}{l}\text { Std } \\
\text { Deviation }\end{array}$ & $\begin{array}{l}\text { Std } \\
\text { Error Mean }\end{array}$ \\
\hline DPVIM & & & 10.692 & 1.127 \\
TVIM & 90 & 48.90 & 7.177 & 0.757 \\
IVIM & 90 & 46.71 & 8.982 & 0.947 \\
Control Group & 90 & 48.11 & 7.843 & 0.827 \\
\hline
\end{tabular}

Table 2: t-test of students' post-treatment scores in RCAT by treatment

\begin{tabular}{lllllll}
\hline $\begin{array}{l}\text { Experimental } \\
\text { Group }\end{array}$ & N & Mean & t & Df & $\begin{array}{l}\text { Significant } \\
\text { level }\end{array}$ & Decision \\
\hline DPVIM & 90 & 48.90 & 2.647 & 178 & 0.009 & Sig. \\
TVIM & 90 & 46.71 & 1.348 & 178 & 0.179 & Not Sig. \\
IVIM & 90 & 48.11 & 2.316 & 178 & 0.022 & Sig. \\
Control Group & 90 & 45.20 & & & & \\
\hline
\end{tabular}

Table 1 presents the mean scores and standard deviations of the students' post treatment scores in RCAT. It reveals that students in all the experimental treatment groups (DPVIM, TVIM and IVIM) performed better than the control group that was exposed to conventional method. It also reveals that the DPVIM had the highest mean score (48.90). However, when the scores were subjected to significant testing using t-test, it was found that while the calculated t-value for main effect of DPVIM (2.647) and IVIM (2.316) are significant (DVIM p-sig. level $0.009<0.05$, IVIM p-sig. level $0.022<0.05$ ), the $t$-value for main effect of TVIM (1.348) is not significant (TVIM - P-sig. level 0.179>0.05 significant level). When the combined effect of the entire treatments was subjected to further statistical analysis, using Analysis of Variance (ANOVA) as shown in Table 3 below. It shows that the main effect of treatments is significant.

Table 3: Analysis of Variance (ANOVA) of students' overall achievement scores.

\begin{tabular}{|c|c|c|c|c|c|c|}
\hline $\begin{array}{l}\text { Source of } \\
\text { Variation }\end{array}$ & $\begin{array}{l}\text { Sum o } \\
\text { Squares }\end{array}$ & Df & $\begin{array}{l}\text { Mean } \\
\text { Square }\end{array}$ & f-ratio & $\begin{array}{l}\text { Sig. } \\
\text { level }\end{array}$ & Decision \\
\hline Treatment & 721.115 & 3 & 240.372 & 3.091 & 0.027 & $\mathrm{P}<0.05$ Sig \\
\hline
\end{tabular}


This implies that even though exposure of the students to the treatments variously impacted on their achievement in reading comprehension, their combined effect does significantly enhance students' achievement in reading comprehension. Therefore the null hypothesis 1 is rejected.

Ho$_{2}$ : There is no significant influence of verbal ability on students' mean achievement scores in reading comprehension.

The data generated to test Hypothesis $2\left(\mathrm{Ho}_{2}\right)$ were analyzed using Analysis of Variance (ANOVA). The results are presented in Table 4.

Table 4: Analysis of Variance of students' overall achievement scores versus verbal ability level.

\begin{tabular}{|c|c|c|c|c|c|c|}
\hline Source of Variation & $\begin{array}{l}\text { Sum } \\
\text { Squares }\end{array}$ & of $\quad$ Df & $\begin{array}{l}\text { Mean } \\
\text { Square }\end{array}$ & f-ratio & $\begin{array}{l}\text { Sig. } \\
\text { level }\end{array}$ & Decision \\
\hline \multicolumn{7}{|l|}{ Main effect } \\
\hline Verbal ability & 3977.931 & 1 & 3977.931 & 61.251 & 0.000 & $P<0.05$ Sig \\
\hline Treatment & 707.345 & 3 & 225.782 & 3.630 & 0.013 & $P<0.05$ Sig \\
\hline
\end{tabular}

RSquared $=0.187$ (Adjusted RSquared $=0.171$ ) level of significance $=0.05$.

The data in Table 4 shows that the main effect of ability level is significant at 0.05 confidence level as the calculated p sig. level value $0.000<0.05$. Therefore, Hypothesis 2 is rejected.

Ho Hore $\quad$ is no significant influence of gender on students' mean achievement scores in reading comprehension.

The data that addressed $\mathrm{Ho}_{3}$ were analyzed using ANOVA as presented in Table 5 below:

Table 5: Analysis of Variance (ANOVA) of students' overall achievement scores versus Gender.

\begin{tabular}{|c|c|c|c|c|c|c|}
\hline Source of Variation & $\begin{array}{l}\text { Sum } \\
\text { Squares }\end{array}$ & of $\mathrm{df}$ & $\begin{array}{l}\text { Mean } \\
\text { Square }\end{array}$ & f-ratio & $\begin{array}{l}\text { Sig. } \\
\text { level }\end{array}$ & Decision \\
\hline Main effect & & & & & & \\
\hline Gender & 0.704 & 1 & 0.704 & 0.009 & 0.929 & $\begin{array}{l}P>0.05 \\
\text { Not Sig. }\end{array}$ \\
\hline Treatment & 721.115 & 3 & 240.372 & 3.091 & 0.027 & $\mathrm{P}<0.05$ Sig. \\
\hline
\end{tabular}

RSquared $=0.027$ (Adjusted RSquared $=0.007$ ) level of significance $=0.05$.

Table 5 indicates that the main effect of gender on achievement in reading comprehension is not significant as the p value of $0.924>0.05$ for f-ratio of 0.009 . Therefore, Hypothesis 3 is not significant. This implies that gender does not exert any significant influence on students' achievement in reading comprehension.

$\mathrm{Ho}_{4}$ : There is no significant interaction effect of mode of presentation of metacognitive strategies and verbal ability on students' mean achievement scores in reading comprehension.

The data generated to test Hypothesis 4 were analyzed using two way Analysis of Variance. The results are presented in Table 6.

Table 6: Analysis of Variance of students' overall Achievement scores by treatment and verbal ability level

\begin{tabular}{|c|c|c|c|c|c|c|}
\hline Source of Variation & $\begin{array}{l}\text { Sum } \\
\text { Squares }\end{array}$ & df & $\begin{array}{l}\text { Mean } \\
\text { Square }\end{array}$ & f-ratio & $\begin{array}{l}\text { Sig. } \\
\text { level }\end{array}$ & Decision \\
\hline \multicolumn{7}{|l|}{ Main effect } \\
\hline Verbal Ability & 3977.931 & 1 & 3977.931 & 61.251 & 0.000 & $\mathrm{P}<0.05$ Sig. \\
\hline Treatments & 707.345 & 3 & 235.782 & 3.630 & 0.013 & $\mathrm{P}<0.05$ Sig. \\
\hline Error & 22860.576 & 352 & 64.995 & & & \\
\hline Total & 831191.000 & 360 & & & & \\
\hline Corrected total & 28129.864 & 359 & & & & \\
\hline
\end{tabular}

RSquared $=0.187$ (Adjusted RSquared $=0.171$ ) level of significance $=0.05$.

The data in Table 6 reveal that the interaction effect of treatment and verbal ability level is significant as the calculated f-ratio (2.937) yielded a $\mathrm{p}=0.03<0.05$. Therefore, Hypothesis 4 is rejected. 
Ho5: There is no significant interaction effect of mode of presentation of metal cognitive strategies and gender on students' mean achievement scores in reading comprehension.

In testing Hypothesis 5, a Two Way Analysis of Variance (ANOVA) was used. The results are shown in Table 7.

Table 7: Analysis of Variance (ANOVA) of students' overall achievement scores by treatment and gender

\begin{tabular}{|c|c|c|c|c|c|c|}
\hline Source of Variation & $\begin{array}{ll}\text { Sum } & \text { o } \\
\text { Squares } & \end{array}$ & df & $\begin{array}{l}\text { Mean } \\
\text { Square }\end{array}$ & f-ratio & $\begin{array}{l}\text { Sig. } \\
\text { level }\end{array}$ & Decision \\
\hline \multicolumn{7}{|l|}{ Main effect } \\
\hline Gender & 0.704 & 1 & 0.704 & 0.009 & 0.924 & $\begin{array}{l}\mathrm{P}<0.05 \\
\text { Sig. }\end{array}$ \\
\hline $\begin{array}{l}\text { Treatments } \\
\text { 2-way interaction effect }\end{array}$ & 721.115 & 3 & 240.372 & 3.091 & 0.926 & $P<0.05$ Sig. \\
\hline Treatment-Gender & 36.215 & 3 & 12.072 & 0.155 & 0.926 & $\begin{array}{l}P>0.05 \\
\text { Not Sig. }\end{array}$ \\
\hline Error & 27376.954 & 352 & 77.775 & & & \\
\hline Total & 831191.000 & 360 & & & & \\
\hline Corrected Total & 28129.864 & 359 & & & & \\
\hline
\end{tabular}

The summary of the Two Way Analysis of Variance (ANOVA) in Table 7 shows that the calculated f value for treatment - gender interaction is not significant $(\mathrm{f}=0.155, \mathrm{df}=3, \mathrm{p}=0.926>0.05$ ). Therefore, Hypothesis 5 is accepted. This implies that the various treatments used for the experiments were not differently effective for male and female students.

Discussion: Hypothesis 1 addressed the effect of instruction on metacognitive strategies on reading comprehension achievement when presented on Drill and Practice, Tutorial and Interactive Modes of Video Instruction. Table 1 on means and standard deviations of students' post test scores in RCAT reveals that students taught metacognitive strategies using DPVIM, TVIM and IVIM had higher mean scores than those taught using conventional methods. Relatedly, even though the t-test of students' post-test treatment scores in RCAT in Table 2 failed to show significant effect of TVIM, the ANOVA of the students' overall achievement scores in Table 3 indicated significant effect of the video modes (DPVIM, TVIM and IVIM) on achievement in reading comprehension. Thus, the video modes of metacognitive instruction significantly impacted on students' achievement in reading comprehension. This finding is in agreement with the findings made by earlier researchers on the effect of video instruction on school achievement (Fajola, 2000; Weeks, Brubakar \& Davis, 2002; Okwo \& Asadu, 2002; McRowland, 2002; Harwood \& McMahon, 2007; Stepsus, 2007; Fante, 2007; Watts, 2007; Philip, Hannafin \& Tripp, 2007). These researchers concluded with qualitative support evidence that video media instructional intervention do positively affect students' school achievement.

McRowland (2002) opined in his study that in addition to broadening the range of students' sensory experience and linguistic competence, video offers a view of the world which is substantially richer than that provided by the teacher's voice and the textbook page. He thus concluded that as language teachers, we should integrate our verbal communication into a system that appeals to a wide range of man's sense of perception and to the totality of his imaginative understanding. In a similar vein, Okwo and Asadu (2002) supported the above proposition and state that video provides stimuli that can lead to and generate predications, speculations and a chance to activate schemata when viewing a visual scene reenacted. In addition, video can stimulate and motivate students' interest, and help learners to predict information, infer ideas and analyze the world that is brought into the classroom via the use of video instruction. Other researchers like Tomalin (2003) and Cannin-Wilson (2006) did not however, find any significance in the performance of students attributable to video instruction. Cannin-Wilson thus advocates that for video to be used in the classroom to improve reading and listening comprehension, it should be shown in segment not as a whole. These segments should be broken down to exploit the macrolistening skills and micro-listening skills from the audio components of the video. Evidence from CanninWilson's study indicates that for as much as the visual component of video may aid understanding, it may detract learners from the main message of the lesson. According to him, evidence showed that attention 
span of the research subjects lowered and the first sign appeared after the first minute and by the end of four minutes, distraction spread all over the video group. More students became distracted after six minutes, and more lost concentration after ten minutes, and only one-third of them kept watching until the end.

In spite of the isolated studies indicating significant effect of video instruction on school achievement, the potency of video as an instructional mode is not in doubt. According to the Integrated Dual-Code Theory which is a major theoretical underpinning of audio-visual learning, the availability of different modes of information processing provided by video is believed to contribute to improved comprehension of language input (Mayer \& Anderson, 1991). This is because video helps learners to build both visual and verbal modes of mental representation as well as connections between them. Mayer (1997) drew on this in developing a generative theory of multi-media learning that assumes that learners actively select relevant verbal information, organize the information into coherent mental representation, and integrate the newly constructed visual representation with one another. Therefore, for learners who lack verbal skills, the availability of visual input would have a contributory influence on their language development. Furthermore, Harben (2009) pointed out that audio-visual context provided by video can aid comprehension as well as activate learner's prior knowledge of the social and cultural aspects of language. Thus the use of video instruction in metacognitive skills enhances success rate in comprehension task as exemplified in this study. The result of this study has provided further empirical justification of this theoretical proposition, and make for a more fruitful utilization of video-instruction to facilitate reading comprehension in Nigeria.

Hypotheses 2 and 4 sought to verify the main effect of verbal ability and the interaction effects of verbal ability and mode of video instruction on achievement in reading comprehension respectively. Analysis of data collected to test hypotheses 2 and 4 as prescribed in Tables 4 and 6 show significant main effect of verbal ability and interaction effect of verbal ability and mode of video instruction on reading comprehension achievement of senior secondary school students. This implies that high verbal ability students performed better in reading comprehension test, and that the treatments used for the experiments were more effective with higher verbal ability students. These findings are in consonance with those of Okpesway (2002), Ede (2005), Tips (2006), Berninger (2006). Berninger reported two studies of second graders at risk for reading disability, which were guided by levels of language and functional reading system theory, and focused on reading comprehension. In the first study it was found that accuracy and rate of word reading and text reading predicted and yielded high comprehension ability and verbal IQ also predicted reading comprehension. In the second study by Berninger, the treatment group (who received out of school integrated verbal aptitude instruction that was supplementary to general reading program improved significantly than the control group. The results from the two studies support vocabulary development and verbal reasoning as essential aids to reading comprehension achievement.

Other studies that investigated the effect of verbal ability, verbal information and media modes on retention and recall established the potency of verbal ability, and the use of video as a mode of instruction of verbal reasoning (Murdock, 2008; Bladdeley, 2008). However, Bladdeley found better short term memory for a few verbal items when the items are presented via the auditory mode than the visual mode. A review of related literature (Penney, 2005) concluded that for tasks involving short term memory, auditory presentation was better than visual presentation of verbal items. The above studies notwithstanding, this study and several others have established that verbal ability is a necessity if a child is to comprehend and learn in school since most school learning tasks are laced to verbal acts. Ayodele (2005) thus opined that pupils' inadequacy in the range and control of language is a very important factor in educational failure in that that deficit generates a vicious circle of difficulties, increasing in magnitude as school life progresses. Ayodele further asserted that in countries like Nigeria where the language of school instruction is not the mother-tongue, the postulate above assumes a greater dimension.

Since ability to comprehend written texts requires some measure of verbal competence, students with low verbal abilities are likely to encounter comprehension difficulties such students would need increased opportunities and experiences such as metacognitive strategy instructions and language video instructions to increase their capacity to comprehend a written passage. Table 5 on Analysis of Variance (ANOVA) of students' overall achievement scores versus gender indicates that the mean scores of male and female students shows no significant difference $(\mathrm{p}=0.924>0.05)$. In the same vein, Table 7 presents the result of ANOVA of students' overall achievement scores by gender and treatment. Again, the table 
shows that the interaction effect of gender and treatments are not significant in exerting influence on achievement in reading comprehension. The no significant main effect of gender agrees with Ezewu (2002), Okoye (2008), Mamah, (2008), Ijiga, (2008) and Onyegebu (2009). The finding however contradicted Ukwungwu (2001) and Ufot \& Awuwole (2001) that found males superior to female. The study by Ukwungwu also indicated that poor achievement of females when compared with males was due to social demands since there was no significant difference in achievement by gender when both sexes were exposed to the same conditions. The result also found no significant interaction effect between video lessons and gender on students' comprehension achievement. This implies that the various strategies or treatments were not differentially effective for male and female students. Several other studies on gender carried out reported conflicting influence of gender on language achievement. However, the most recurrent finding is that females often outperform male in tasks involving language use.

\section{Conclusion}

Video is a medium which permits the selection and presentation of educational information in an audio visual context. It combines audio stimuli with visuals in the form of illustration, pictures, images, colors, impressions, replicas, etc., which help learners to see the immediate meaning in language, including comprehension, through the use of paralinguistic elements it provides. Despite the potential of video in education, this medium of instruction is rarely seen to be used in our schools. Hardly can one enter a classroom in public and private schools in Nigeria and find video-based instruction being implemented. Just as video is considered a potent medium for language instruction, metacognitive role in reading comprehension is considered to be one of the most important contributions cognitive psychology has made to field of reading in education. Throughout the 1980s and 1990s, many researchers focused on the relationship of metacognitive skills to reading comprehension (Jacob \& Paris, 1987; Markman \& Glorin, 1981; Paris \& Jacob 1994; Paris \& Meyers, 1992). The results of these researches gave rise to focus towards developing reading comprehension skills through metacognitive strategy instruction. These studies demonstrate that successful comprehension does not occur automatically. Rather, it depends on directed cognitive effort, referred to as metacognitive processing. Through metacognitive strategies, a reader allocates significant attention to controlling, monitoring and evaluating the reading process (Pressley, 2000).

This study has carefully combined the effect of the potentials of video and metacognitive strategies on secondary school students' achievement in reading comprehension. Since the study results have established significant influence of metacognitive strategies on reading comprehension when presented on video modes, language teachers should no longer restrict their reading comprehension instructions to the conventional lecture method. Instead they should enrich their instruction with video displays of essential points and habits. The study also established that students need a reasonable measure of verbal reasoning capabilities to be able to comprehend texts. This is evident in the finding which relates high verbal ability to higher achievement in reading comprehension. Thus, measures of verbal ability can be used to provide the best estimate of how much a reader could get from written texts. Textbooks and research papers on gender and sex routinely cite sex difference and students' achievement, especially in language competences regarding verbal fluency and comprehension, as established facts. Unfortunately researches on gender and language achievement are not consistent in establishing gender difference in language skill attainment. Such is the case of this research which failed to establish gender influence in reading comprehension achievement. The inconsistency in the results of gender - language achievement interaction effect calls for more researches to be conducted to put the matter to rest.

Recommendations: Based on the results of this study, the following recommendations are made:

- Language teachers should make use of video instruction in developing comprehension skills of secondary school students in Nigeria. Video used in class should be interpretive and to the point. The visual should show reasonable subject matter that would enhance comprehension, heighten visual acuteness and illustrate the target point of comprehension studies. The teacher in using video for instruction should avoid the use of unnecessary distracters, over-crowded and violent visuals.

- Before presenting the video, the teacher should sensitize the students in the vital subject matter to be learned from the video presentation, and what they are expected to watch out for and do while the students view the video, the teacher should remain in class with the students to observe their reactions and to attend to what they do not understand. After viewing the video, 
the teacher should review and clarify complex points, encourage discussion, explain and assign follow up activities. It is also important to ensure the suitability, length, clarity and completeness of the video materials.

- Pre-service and in-service training programs for teachers should stress mediated instruction. This will ensure that teachers become proficient in the use of video and other media materials for teaching.

- Efforts should be made by language teachers to develop students' verbal ability since it is a prerequisite to attainment of reading comprehension competence.

- Teacher education curriculum should be re-developed to include training in the use of video and multi-media for teacher trainers.

- Seminars, workshops and symposia should be organized by Language Teachers Association of Nigeria (LATAN) and Reading Association of Nigeria (RAN) to study and enlighten language teachers on the findings of this study.

\section{References}

Ayodele, S. 0. (2005). The use of computer and video to assist classroom instruction. Ibadan|: Power House Press.

Balatova, I. (2004). Impact of video on the comprehension skills of core French students. Canadian Modern Language Review, 50(3), 506-531.

Bazerman, C. (1985). Physicist reading physics: Schema-laden purposes and purpose-laden schema. Written Communication, 2(1), 3-23.

Berninger, V. W. (2006). Paths of reading comprehension in at-risk second-grade readers. Journal of Learning Disabilities, 39(4), 334-351.

Bladdeley, E. O. (2008). Verbal reasoning as correlate of language element retention and retrieval. Journal of Experimental Education, 54(4) 181-188.

Canning-Wilson, C. (2006). Research in visuals. Invited paper for the video Special Interest Group at the Internal TESOL, Arabia 2005 conference, Hilton Hotel.

Choi, H. J. \& Johnson, S. D. (2007). The effect of problem-based video instruction on learner satisfaction, comprehension and retention in college course. British Journal of Educational Technology, 38(1), 885-895.

Choi, H. J. \& Johnson, S. D. (2005). The effect of context-based video instruction on learning and motivation in online courses. The American Journal of Distance Education, 19(4), 215-227.

Donin, J., Graves, B. \& Goyette, E. (2004). Second language text comprehension: Processing within a multilayered system. The Canadian Modern Language Review, 6(1), 53-76.

Ede, S. O. (2005). Relationship between verbal ability and achievement in secondary school social studies in southern Nigeria. Language in India, 5(2) 22-28.

EI-Koumy, A. (2004). Effect of self-assessment of reading processes versus products on EAP readers' comprehension. Journal of Reading \& Literacy, 3, 1-22.

Eze, U. N. (2007). Effect of self-regulating strategies on reading comprehension achievement of senior secondary school students. International Journal of Science and Technology Education, 2(1), 1 -1 9.

Ezewu, E. E. (2002). An experimental study of the. effect of mastery learning strategy on achievement in French at the secondary school level. Educational Review, 2(1), $12-23$.

Fajola, 0. 0. (2000). Relative effectiveness of three modes of video tape instructional strategies on students' learning outcomes in biology. Educational Review, 12(4), 78-85.

Fante, C. H. (2007). Effects of video instruction on developmental English instruction at a community $\begin{array}{lllll}\text { college. } & \text { Retrieved } & \text { June } & 2007, & \text { from }\end{array}$ file:MSERVER/sharedDocs/Effects\%2020video\%20instruction\%20 on...

Flood, J., Lapp, P. \& Fisher, D. (2003). Reading comprehension instruction. In J. Flood, D. Lapp; J. E. Squire; \& J. M. Jenson (Eds.). Handbook of research on teaching the English language arts. Mahwa, NJ: Lawrence Eribaum Associates Inc.

Giftma, C. U. (1973). Developing verbal aptitude in ESL classroom. Boston: Alien and Bacon.

Goldman, I. B. (2005). Using hyper-media lo improve instructional presentation. American Journal of Teacher Education, 41(3), 66-78.

Hannafin, M. J. \& Colamaio, M. A. E. (2007). The effect of variation in lesson control and practice on learning from interactive video. ECTJ, 35(4), 203-215.

Harben, P. (2009). An exercise in applying pedagogical principles to multimedia CALL materials design ReCALL, 11(3), 25-33. 
Harwood, W. S. \& McMahon, M. M. (2007). Effects of integrated video media on student achievement and attitude in high school chemistry. Wiley Intel-science Journal, 10(7), Retrieved October 17, 2008 from http://www.interseicnce.willey.com/cgibim/abstract/45500/ABSTRACT? CRHTRY $-1 \& 5$.

Ho, C. K. (2008). Emerging technologies digital video update: YouTube, flash, high-definition. Language Learning \& Technology, 11(1), 16-21.

Ibode, F. O. (2010). Effect of Computer Assisted Instruction (CAI) and Video Tape Instruction (VTI) on achievement in, and attitude to English language. Unpublished Doctoral thesis, institute of Education, University of Ibadan, Ibadan, Nigeria.

Ijiga, P. A. (2008). Effects of prior knowledge of behavioral objectives and study questions on senior secondary school students' achievement in reading comprehension in Otukpo Metropolis. Unpublished PhD thesis, Benue State University, Makurdi, Nigeria.

Jacobs, J. E. \& Paris, S. G. (1987). Children's metacognition about reading: Issues in definition, measurement, and instruction. Educational Psychology, 22, 255-278.

Lobb, W. H. \& Cartwright, L. (2007). Interactive video tape and videodisc language packages. In J. G. Hcdberg, J. Steele \& M. Mooney (Eds.), Converging Technologies. Selected papers from EdTech. ${ }^{\mathrm{H}}$ ) 0, 158-162, Canberra: AJET Publications. Retrieved on October 27, 2007 from http://www.aset.oru.au/confs/edteeh90/iobb.htmi

Mamah, M. C. (2008). Effect of Audio picture instructional system on achievement in Biology. Unpublished M.Ed Research Project, University of Nigeria, Nsukka.

Mackey, T. P. \& Ho, J. (2008). Exploring the relationships between web usability and students' perceived learning in web-based multimedia (WEMM) tutorials. Computer and Education, 50, 386-409.

Markman, E. M. \& Glorin, L. (1981). Children's ability to adjust their standards for evaluating comprehension. Journal of Educational Psychology, 73, 320-325.

Mayer, R. E. (1997). Multimedia learning: Are we asking the right question? Educational Psychologist, 32(1), 1-19.

Mayer, R. E. \& Anderson, R. B. (1991). Animation need narration: An experiment test of a dual coding hypothesis. Journal of Educational Psychology, 83,484-490.

Mayer, R. E. \& Moreno, R. (2003). Animation as an aid to multimedia learning. Educational Psychology Review, 14, 89-99.

McRowland, P. (2002). Effects of video instruction on conceptual understanding and achievement of college students exhibiting individual differences in learning. Journal of Audio-Visual Research, 35(7), 103-115.

Mikkink, C. A., Hulstin, T. \& Smith, R. B. (2005). Enhancing children's comprehension through instruction in narrative structure. Journal of Reading Behavior, 28, 7-16.

Murdock, B. B. (2008). Modality effect in short term memory: shortage or retrieval? Journal of Experimental Psychology, 77, 79-86.

Ogunkola, B. J. (1998). Gender differences in the performance of secondary school students in theoretical and practical biology test in Nigerian environment. Journal of Research in Education, 2(1), 88-98.

Ogunmilade, C. A. (1989). Media in education. Ife: University of Ife Press.

Okoye, N. N. (2008). Are boys better than girls in Mathematics and English language performances? Psychology for Everyday Living, 2(21), 12-19.

Okpesway, T. B. (2002). The relationship between verbal ability and students' achievement in economics. Journal of Language and Literacy Research, 2(3), 93-106.

Okwo, F. A. \& Asadu, C. C. (2002). Comparative effect of three modes of mediated instruction on secondary school students' achievement in physics. International Journal of Arts and Technology Education, 2(1), 137-144.

Omoniyi, T. T. (2007). Effects of televideo individualized and group controlled instructions on the achievement and attitude of students in educational technology. Illorin Journal of Education, 4(2), 57-69.

Onyegegbu, N. (2009). Effect of video and audio-rolliograph on students' achievement and retention in the understanding of schiotomiasis. Unpublished PhD thesis Faculty of Education, University of Nigeria, Nsukka.

Ortiz, F. L. (2004). Standard teacher training manual for teachers of English as a second language. Teacher Education Quarterly, 17, 87-99.

Ososona, S. (1997). Effect of video tape recording (VTR) presentation on student teachers attitudes and achievement in selected teacher training colleges in Oyo State. African Journal of Education, 3(2), 231-244. 
Oyetunde, T. O. \& Muodumogu, C. A. (1999). Effective English teaching in primary and secondary schools. Jos: Conference on Educational Improvement.

Paris, S. G. \& Jacobs, J. (1994). The benefits of informed instruction for children's reading awareness and comprehension skills. Child Development, 55, 2083-2093.

Paris, S. G. \& Meyers, M. N. (1992). Comprehension monitoring, memory, and study strategies of good and poor readers. Journal of Reading Behavior, 13, 5-22.

Penney, C. G. (2005). Modality effects in short-term verbal memory. Psychological Bulletin, 88, 68-84.

Philips, T. L., Hannafin, M. J. \& Tripp, S. D. (2007). The effect of practice and orientating activities on learning from interactive video. Educational Communication and Technology Journal, 36(2), 93102.

Pressley, M. (2002). What should comprehension instruction be the instruction of? In M. L. Kamil; P.B. Mosenthal; P.O. Pearson, \& R, Barr (Eds.), Handbook of Reading Research Volume III. Mahwah NJ: Erlbaum. P.545-561

Pressley, M. \& Afflerbach, P. (1995). Verbal protocols of reading: The nature of constructively responsive reading. Hillsdale NJ: Erlbaum.

Rajasekar, S. (2009). Innovative video modes and methods, A lecture delivered in the in-service programme for the members of staff of Faculty of Education. organized by Faculty of Education, Annamalai University, August 29.

Rammal, S. M. (2005). Using video in the EFL classroom. A paper presented at CDELT 25 ${ }^{\text {th }}$ Annual Symposium, Ein-Shams University, Cairo, Egypt.

Robinson, H. A. (2000). Teaching reading and study strategies: New millennium edition. Boston: Alien \& Bacon Inc.

Rose, C. (2003). How to teach Biology using the movie science of cloning people, resurrecting the dead, and combining flies and humans. Public Understanding of Science, 12(3), 289-296.

Rubin, L. (2001). The curriculum in perspective: Schooling and subject matter. In L. Rubin (Ed.). Curriculum handbook, (pp. 111-119). Boston: Alien \& Bacon Inc.

Seo, K. (2002). The effect of visuals on listening comprehension: A study of Japanese learners listening strategies. International Journal of Listening, 16(5), 57-81.

Simpson, K. O., Cumley, G. D. \& Novak, B. (2007). Effects of three video instructional modes on the performance of novice professional students with AAC technology. Retrieved September 7, 2007 from http://www.informawQrld.com/snipp/contentcontenl 9738552787-dh-aU.

Stepsus, P. A. (2007). To determine whether videotape instruction is more effective for learning than the traditional didactic approach, Retrieved October 7, 2007 from http://www.eric.ed.gov/ERIC/webportal/custom/portlets/recordDetails/detailmini.jsp

Tips, M. (2006). Effect of instruction in verbal reasoning strategies (analogies) on a college reading improvement course. Journal of Verbal Behavior and Cognition, 12(6), 230-241.

Tomalin, B. (2003). Teaching young children with video. In S. Stempleski, \& P. Areario, (Eds.) Video instruction. New York: Prentice Hall.

Ufot, E. R. \& Awuwoloye, E. O. (2001). Sex stereotyping in WAEC SSCE/GCE science subject examination. A paper presented at the Common wealth African Regional Workshop on gender stereotype in science education, Accra, Ghana.

Ukwungwu, J. O. (2001). A meta-analysis of empirical studies on gender-related differences in achievement and interest in science. Unpublished PhD thesis, University of Nigeria, Nsukka.

Watts, C. (2007). Interactive video: What the students say. CALICO Journal, 12, 120-129.

Weeks, D. L., Brubaker, J. \& Davis, M. (2002). Video instruction versus illustrations for influencing quality of performance, motivation, and confidence to perform simple and complex exercises in healthy subjects. Physiotherapy Theory and Practice, 18(2), 65-73.

Yang, Y. (2005). Reassessing Readers' Comprehension Monitoring (on-line). Available at: http://nflre.hawaii.edu./rfl/ApriI2002/yang/yang.html. 